\title{
A ATUAÇÃO DO ASSISTENTE SOCIAL NO PODER JUDICIÁRIO DO ESTADO DO RIO DE JANEIRO EM TEMPOS DE PANDEMIA COVID-19
}

\section{THE PERFORMANCE OF THE SOCIAL WORKER IN THE JUDICIARY OF THE STATE OF RIO DE JANEIRO IN TIMES OF COVID-19 PANDEMIC}

\author{
Vivian Maria Rodrigues Loureiro Felix \\ Roberta Cristina Bastos Barreto* \\ Andreia Cristina Alves Pequeno ${ }^{\star \star \star}$ \\ Melissa Botelho de Oliveira ${ }^{\star \star \star}$
}

Resumo: Este artigo tem por objetivo refletir sobre a atuação do assistente social no Tribunal de Justiça do Estado do Rio de Janeiro, a partir da experiência das autoras em duas áreas distintas de intervenção no âmbito da referida instituição: Execução da curatela e Direito de Família e da nova dinâmica de trabalho que emerge com a pandemia da Covid-19 que assola o Brasil e o mundo.

Palavras-Chave: Judiciário. Serviço Social. Pandemia. Teletrabalho. Direitos.

Abstract: This article aims to reflect on the role of the social worker in the Court of Justice of the State of Rio de Janeiro, based on the experience of the authors in two distinct areas of intervention within the aforementioned institution: Execution of the trustee and Family Law and new work dynamic that emerges with the Covid-19 pandemic that is plaguing Brazil and the world.

Keywords: Judiciary. Social Service. Pandemic. Teleworking. Rights.

\footnotetext{
* Assistente Social do Tribunal de Justiça do Estado do Rio de Janeiro. Mestre em Serviço Social pela Pontifícia Universidade Católica do Rio de Janeiro - PUC-RIO. E-mail: vivianmaria@tjrj.jus.br

** Assistente Social do Tribunal de Justiça do Estado do Rio de Janeiro. Especialista em Direitos Humanos pela Universidade Candido Mendes - UCAM. E-mail: robertabastos@tjrj.jus.br

${ }^{\star \star \star}$ Assistente Social do Tribunal de Justiça do Estado do Rio de Janeiro. Mestre em Serviço Social pela Universidade do Estado do Rio de Janeiro - UERJ. E-mail: andreiacap@tjrj.jus.br

${ }^{* * \star *}$ Assistente Social do Tribunal de Justiça do Estado do Rio de Janeiro. Mestre em Serviço Social pela Universidade do Estado do Rio de Janeiro - UERJ. E-mail: melissabotelho@tjrj.jus.br
} 


\section{INTRODUÇÃO}

O ano de 2020 inova com a presença de um novo personagem no palco internacional da vida. Acirrando a luta pela sobrevivência, a chegada da Covid-19, com manifestação pandêmica, em vários países espalhados pelos cinco continentes desnuda o cenário mundial de desigualdades sociais decorrente da forma como o sistema capitalista vem estruturando o modo de vida nos últimos séculos. Além de evidenciar o descompromisso de alguns governantes com a garantia de direitos à população.

A pandemia da Covid-19 emerge no bojo de instabilidades e tensões historicamente determinadas que rege o modo de produção capitalista e configura-se em uma crise sanitária cujo impacto, entretanto, não atinge apenas a área da saúde, mas repercute nas diferentes esferas da vida social atingindo de modo absolutamente violento a população com baixo ou sem qualquer poder aquisitivo.

Este seguimento populacional tem sido a maior vítima deste tempo histórico ao perder até mesmo suas vidas, já que no bojo do projeto neoliberal o progressivo desmonte e desfinanciamento das políticas sociais públicas, em especial da saúde, tem resultado na falta de acesso a atendimento médico, vagas para internação, medicação e aparelhos que auxiliem no tratamento e progressiva recuperação dos doentes.

Segundo dados da Organização Mundial da Saúde (OMS), o Brasil registra a cifra de 174.531 mortes (ESTATÍSTICAS, 2020) e a cidade do Rio de Janeiro apresenta a média diária de 558 casos confirmados e um total de 13.465 óbitos pela doença (INSTITUTO PEREIRA PASSOS, 2020). Como pode-se observar, os números apresentados são alarmantes e apontam para uma realidade ainda mais cruel quando analisados do ponto de vista social.

Ao movimentar a dinâmica da vida e da morte, a Covid-19 repercute nos mais diferentes aspectos da vida, atingindo relações pessoais, comerciais e laborativas. A vida privada e o mundo do trabalho se transformam de modo repentino, sem qualquer possibilidade de um planejamento prévio diante da imperativa necessidade de isolamento social, medida fundamental para conter a disseminação do vírus. Enquanto alguns seguimentos econômicos comemoram aumento de sua lucratividade, a população colhe uma maior precarização de suas condições de vida 
e os trabalhadores enfrentam a reconfiguração das relações, das condições, das ferramentas e dos processos de trabalho'.

Compondo a parcela populacional dos trabalhadores tipificados como servidores públicos, os assistentes sociais que exercem sua profissão no cenário do Judiciário estadual também são atingidos por todas essas mudanças e são convocados a redesenhar sua forma operacional para atender os padrões de produtividade institucional, mas, sobretudo, para assegurar alguma possibilidade de atendimento à parcela populacional que depende de decisões judiciais para resolver questões relevantes para suas vidas.

Assim, por meio deste artigo, objetiva-se compartilhar uma reflexão sobre os limites e desafios postos ao Assistente Social no judiciário neste duro tempo histórico de aumento de violações de direito sob o manto da pandemia da Covid-19. A metodologia adotada para este trabalho foi análise histórico institucional, somada a pesquisa de caráter qualitativo². Trata-se de um período no qual alimentar uma intervenção profissional que se efetive com criticidade, comprometida com o projeto ético-político ${ }^{3}$ da profissão e que favoreça o acesso a direitos aos sujeitos que

\footnotetext{
1 "No Brasil, onde vivenciamos desde sempre formas intensas de exploração do trabalho e de precarização ilimitada, as consequências são ainda mais perversas do ponto de vista social. Só para dar alguns exemplos, antes da pandemia, mais de $40 \%$ da classe trabalhadora brasileira encontravase na informalidade ao final de 2019. No mesmo período, uma massa em constante expansão de mais de cinco milhões de trabalhadores/as experimentava as condições de uberização do trabalho, propiciadas por aplicativos e plataformas digitais, o que até recentemente era saudado como parte do "maravilhoso" mundo do trabalho digital, com suas "novas modalidades" de trabalho on-line que felicitava os novos "empreendedores (ANTUNES, 2020 p.7)."

${ }^{2}$ De acordo com Minayo (1994): A pesquisa qualitativa responde a questões muito particulares. [...] ela trabalha com o universo de significados, motivações, aspirações, crenças, valores e atitudes, o que corresponde a um espaço mais profundo das relações, dos processos e dos fenômenos que não podem ser reduzidos à operacionalização de variáveis [...] (MINAYO, 1994, p.21-22). Esta abordagem permitiu conhecer e ampliar a compreensão através do acompanhamento social de homens, mulheres e/ou de famílias que apresentam suas histórias e vivencias no serviço social quando acessam a justiça.

${ }^{3} \mathrm{O}$ termo Projeto ético-político profissional significa uma projeção coletiva que envolve sujeitos individuais e coletivos (daí a ideia de projeto) em torno de uma determinada valoração ética (daí o termo ético) que está intimamente vinculada a determinados projetos societários (daí o termo político, no seu sentido mais amplo) presentes na sociedade que se relacionam com diversos projetos coletivos em disputa na mesma sociedade (daí o termo profissional, expressando a particularidade de uma categoria).

O projeto ético-político do Serviço Social não foi construído de maneira efêmera. Sua gênese se localiza na segunda metade da década de 70 e teve como marco o III CBAS, conhecido como "Congresso da Virada". Esse mesmo projeto avançou nos anos 80 , num processo de redemocratização da sociedade brasileira, recusando o conservadorismo profissional ainda presente no Serviço Social brasileiro. Constata-se o seu amadurecimento na década de 1990, período de profundas transformações societárias que afetam a produção, a economia, a política, o Estado, a cultura, o trabalho, marcadas pelo modelo de acumulação flexível e pelo neoliberalismo. O projeto ético-político profissional hoje
} 
acessam o judiciário é um imperativo que evidencia de modo fulgente as escolhas ético-políticas ${ }^{4}$ que fazem os profissionais componentes do Serviço Social.

\title{
2 O SERVIÇO SOCIAL NO JUDICIÁRIO ESTADUAL E OS IMPACTOS DA COVID- 19
}

O Serviço Social no contexto jurídico configura-se como uma especialidade do mundo do trabalho que atua com as expressões da questão social ${ }^{5}$, em interlocução com o Direito, para ofertar subsídios à tomada de decisão pela autoridade judiciária (CHUAURI, 2001).

No Brasil, o ingresso do Assistente Social no Tribunal de Justiça do Estado do Rio de Janeiro coincide com a gênese da profissão em território nacional. Com base na experiência Europeia, na década de 1930 é tecida a teia das condições sóciohistóricas que possibilita o surgimento desta nova especialização do mundo do trabalho que emerge no bojo dos interesses cristãos da Igreja Católica e do Estado.

Em seu projeto de retomar status, reconhecimento e espaços perdidos ao longo do tempo, a Igreja Católica investe na reconquista da hegemonia visando a disseminação da doutrina cristã e a conquista de novos adeptos e de espaços na sociedade. Assim, adota mudanças em suas bases operacionais investindo na qualificação de suas ações de filantropia, de ajuda ao próximo e no eixo educação formação profissional. Abraça o investimento na formação deste novo profissional, assistente social, ao vislumbrar que este pode ser um agente importante para o projeto de reforma societária de bases cristã-católica.

\begin{abstract}
Como profissão inscrita na divisão do trabalho, o Serviço Social surge como parte de um movimento social mais amplo, de bases confessionais, articulado à necessidade de formação doutrinária e social do laicato, para uma presença mais ativa da Igreja Católica no "mundo temporal", nos inícios da década de 30. Na tentativa de recuperar áreas de influências e privilégios perdidos, em face da crescente secularização da sociedade e das tensões presentes nas
\end{abstract}

ainda se encontra em construção e fortemente tensionado pelos rumos neoliberais da sociedade e por uma nova reação conservadora no seio da profissão (YASBECK, 2004).

${ }^{4}$ Ao fazer referência às escolhas ético-políticas, tem-se por objetivo salientar a dimensão do trabalho profissional que tem relação direta com os princípios éticos e políticos que norteiam o exercício da profissão de Serviço Social, princípios estes delimitados no Código de Ética do Assistente Social (LEI 8.662/1993) (BRASIL, 1993).

5Segundo lamamoto (1997, p. 27), a Questão Social pode ser definida como o conjunto das expressões das desigualdades da sociedade capitalista madura, a produção social é cada vez mais coletiva, o trabalho torna-se mais amplamente social, enquanto a apropriação dos seus frutos se mantém privada, monopolizada por uma parte da sociedade. 
relações entre Igreja e Estado, a Igreja procura superar a postura contemplativa (IAMAMOTO, 2013, p. 18).

O Estado, por sua vez, no contexto do governo de Getúlio Vargas, que se materializa na fase do capitalismo monopolista, é instado a reinventar sua forma de enfrentar a luta dos trabalhadores por dignas condições de vida, visto que combater as demandas da classe trabalhadora apenas como caso de polícia não mais se evidencia suficiente. Adotando uma gestão de bases ditatoriais, mas reconhecendo a importância de conquistar sua legitimidade, o Estado Novo incorpora algumas reivindicações dos trabalhadores e implementa medidas populistas que favorecem o controle da massa populacional. A criação do Ministério do Trabalho, a garantia de alguns direitos trabalhistas assegurados na inovadora legislação Consolidação das Leis Trabalhistas, a formatação dos sindicatos e a adoção de políticas assistencialistas e de controle social que seriam executadas pelos recém surgidos assistentes sociais garantem a Vargas entrar para a história como o "pai dos pobres" (SILVA, 2006).

É nesta dinâmica contraditória da história que nasce e, gradativamente, se consolida em terras brasileiras a profissão de Serviço Social, que como tantas outras na caminhada de sua edificação pode atender a interesses múltiplos e diversos, mas sempre desempenhando uma função social que coaduna com o tempo sócio-histórico e com os interesses econômico-políticos vigentes.

Neste sentido, elucida Netto:

\begin{abstract}
É somente na ordem societária comandada pelo monopólio que se gestam as condições histórico-sociais para que, na divisão social (e técnica) do trabalho, constitua-se um espaço em que se possam mover práticas profissionais como as do assistente social. A profissionalização do Serviço Social não se relaciona decisivamente à "evolução da ajuda", à "racionalização da filantropia" nem à "organização da caridade", vincula-se à dinâmica da ordem monopólica. É só então que a atividade dos atentes do Serviço Social pode receber, pública e socialmente, um caráter profissional (...) o serviço Social é indivorciável da ordem monopólica - ela cria e funda a profissionalidade do Serviço Social (NETTO, 1982, p. 69).
\end{abstract}

Novato como profissão, mas já reconhecido em sua potencialidade, ainda sem contar com um significativo corpo de profissionais formado, o Serviço Social já desperta o interesse de diversos espaços laborativos, inclusive do Judiciário.

Criado em 1923, no Rio de Janeiro, então capital do Brasil, o primeiro Juizado de Menores do Brasil e da América Latina, teve como primeiro juiz o professor e jurista 
José Candido de Albuquerque Melo Mattos, ator importante na aprovação da primeira legislação específica ao público infanto-juvenil: Código de Menores, em 1927, que passa a assegurar que pessoas menores de 14 anos não poderiam ser submetidas a processo penal e que aqueles entre 14 e 18 anos não seriam julgados como adultos, mas seriam submetidos a um tipo de processo diferenciado regulado por esta nova legislação (BRASIL, 1927). Com a tarefa de enfrentar as causas da infância, a grave situação em que dezenas de crianças se encontravam nas ruas da Capital nacional, o Judiciário vislumbrou que os assistentes sociais teriam contribuição a dar neste desafio.

Assim, ainda em fins dos anos 1930 fomentando a ideia de necessidade de profissionais com formação técnica especializada, o Judiciário da Capital tem a iniciativa de um curso direcionado para pessoas que desejavam atuar como assistentes sociais. Desde então conta com a atuação desta categoria profissional em seu cenário, inicialmente nas dependências do Laboratório de Patologia Social, setor que dava suporte ao agir da autoridade judiciária infanto-juvenil.

A partir desta experiência, os assistentes sociais foram gradativamente, ao longo das décadas seguintes expandindo sua atuação e ocupando espaço nas diferentes áreas do contexto Judiciário.

Neste início do século XXI, a contribuição do Serviço Social ao Judiciário Estadual do Rio de Janeiro se efetiva nas seguintes áreas: infanto-juvenil (medidas protetivas e socioeducacionais), família (guarda, convivência familiar), violência doméstica, criminal, execução penal, orfanológica (tutela / curatela), saúde do trabalhador, acesso ao registro civil.

Atualmente, a principal demanda encaminhada ao assistente social pelos Juízes é a elaboração do Estudo Social que enseja a emissão de um parecer social que se constitui como a análise acerca dos dados obtidos durante a realização do estudo social, a partir da fundamentação teórica, ética e técnica que orienta nosso trabalho. De acordo com Fávero (2003), o estudo social,

[...] tem por finalidade conhecer com profundidade, e de forma crítica, uma determinada situação ou expressão da questão social, objeto da intervenção profissional - especialmente nos seus aspectos socioeconômicos e culturais. (FÀVERO, 2003, p. 42-43).

Desvelar a realidade social dos sujeitos que são partes dos processos judiciais, em última análise, é identificar as inúmeras expressões da questão social LexCult, Rio de Janeiro, ISSN 2594-8261, v.4, n.3, set./dez. 2020, p. 195-214 
vivenciadas cotidianamente por estes indivíduos. Por vezes, as demandas apresentadas ao Poder Judiciário pelos sujeitos que experienciam tais expressões da questão social é a opção que se revela como a derradeira, frente ao fracasso das tentativas de serem atendidos pelo Poder Executivo através das políticas sociais, que se apresentam fragmentadas e precárias no cenário contemporâneo, marcado pelos impactos da política neoliberal.

Ressalta-se que decifrar, então, este processo de judicialização da questão social, é de fundamental importância, tendo em vista que esta se constitui como objeto de intervenção do assistente social. A questão social é compreendida aqui como o conjunto das diversas desigualdades sociais forjadas na relação capital-trabalho.

A conjuntura inaugurada pela pandemia, com a necessidade de assegurar o isolamento social, adensa o uso das Tecnologias de Informação e Comunicação (TICs) para diversas categorias profissionais, inclusive para o Serviço Social, impactando de modo contundente o processo de trabalho de muitos trabalhadores.

Segundo Antunes (2020):

Dada a divisão sociossexual e racial do trabalho em sua nova morfologia, as mulheres trabalhadoras brancas sofrem mais que os homens brancos (basta ver que os altos índices de violência doméstica e feminicídio se ampliam durante a pandemia), enquanto as trabalhadoras negras são ainda mais penalizadas que as brancas (veja-se o exemplo das trabalhadoras domésticas no Brasil, que totalizam 6,2 milhões, das quais $68 \%$ são negras). (...) É desnecessário acrescentar, então, que as discriminações de classe, gênero e raça se intensificam ainda mais quando contemplamos as trabalhadoras indígenas, imigrantes e refugiadas (ANTUNES, 2020, p. 14).

Para os assistentes sociais o fenômeno da Covid-19 potencializa o debate sobre as condições éticas, técnicas e materiais do exercício profissional, pois a intervenção profissional demanda reiterado contato pessoal com a população nas realizações das entrevistas e visitas técnicas. Além destas particularidades, a categoria sofre ainda os impactos que atingem aos demais trabalhadores: a intensificação do trabalho feminino e o aprofundamento da divisão sexual do trabalho; diluição entre público e privado, bem como a invasão do trabalho nas várias dimensões da vida privada, com expressiva diminuição do tempo de descanso, visto que a utilização massiva dos recursos tecnológicos acentua o caráter intermitente do trabalho.

Esta atual realidade pandêmica afeta ainda o cotidiano da rede do sistema de garantia de direitos, da qual fazem parte os diversos atores institucionais - Defensoria 
A ATUAÇÃO DO ASSISTENTE

SOCIAL NO PODER JUDICIÁRIO

DO ESTADO DO RIO DE JANEIRO

EM TEMPOS DE PANDEMIA COVID-19
Vivian Maria Rodrigues Loureiro Felix Roberta Cristina Bastos Barreto Andreia Cristina Alves Pequeno Melissa Botelho de Oliveira

Pública, Ministério Público, Centro de Referência de Assistência Social (CRAS), Centro de Referência Especializado de Assistência Social (CREAS), Centro de Atenção Psicossocial (CAPS), instituições de saúde e de acolhimento. E produz um tensionamento entre os pressupostos éticos-políticos, entre as reais condições de trabalho das equipes e a realidade das condições de vida da população atendida, que possuem ou não acesso as tecnologias necessárias às modalidades do trabalho não presencial (trabalho remoto, "online", teletrabalho e home office). Emergem neste contexto, sem planejamento e debate maduros novas rotinas e estratégias de atuação que na maioria das vezes não assegura atendimento a todos e nem o adequado acesso aos direitos pela população.

As diversas expressões da vulnerabilidade que a população brasileira usuária dos serviços governamentais está submetida, neste atual contexto de isolamento social, de precarização das relações de trabalho, de desmonte de políticas públicas, foi desnudada nas suas complexidade e desumanidade para toda sociedade.

\section{A EXPERIÊNCIA DA ATUAÇÃO PROFISSIONAL NA EXECUÇÃO DA CURATELA}

A curatela é um instituto jurídico muito antigo na história da humanidade. Suas raízes decorrem de sementes que se perpetuam desde o período do Direito Romano, com registros a respeito deste encargo ainda na Lei das XII Tábuas. A Quinta Tábua trazia a previsão de que uma pessoa que torna-se louca ou pródiga poderia ser colocada, assim como seu patrimônio, sobre a responsabilidade de outrem (BRASIL, c1995).

Com a caminhada da humanidade esta previsão normativa foi ganhando particularidades no cenário das distintas nações e neste século XXI já resultou extinta em alguns países, sendo substituídas por outras medidas diante do grave impacto da curatela no exercício da capacidade civil, da autonomia e liberdades dos sujeitos.

No Brasil, a curatela foi acolhida logo nas primeiras normativas nacionais e até hoje está presente no ordenamento jurídico. A lei mais recente data de 2015 - Lei Brasileira de Inclusão (LBI), também denominada Estatuto da Pessoa com Deficiência (EPD) - e é fruto de um importante debate internacional e nacional que mobilizou diversos personagens da histórica luta por direitos das pessoas com deficiência promoveu importantes modificações em seu regramento (BRASIL, 2015). 
O Estatuto da Pessoa com Deficiência reafirma (BRASIL, 2015) em território nacional um ideário diferenciado no que se refere aos direitos das pessoas com deficiência e da aplicabilidade do instituto da curatela, o qual já havia sido inaugurado com a ratificação feita pelo Brasil da Convenção Internacional de Direitos da Pessoa com Deficiência, aprovada pela Organização das Nações Unidas (ONU) em 2017.

As principais mudanças implantadas por este novo ordenamento jurídico redesenham o conceito da capacidade civil, de deficiência e de curatela e afirmam o princípio da igualdade e da dignidade aquelas com idade menor de 16 anos. Enquanto o conceito de deficiência se divorcia da definição do diagnóstico médico para convocar uma avaliação multidisciplinar que estabeleça a relação do diagnóstico e das condições do sujeito com as barreiras presentes em sua realidade de vida. Com isto, aplicação da curatela não deve decorrer como consequência imediata de um diagnóstico médico, mas deve ser aplicada com caráter excepcional e ser aplicada com parcimônia, na exata medida da necessidade de cada sujeito mediante avaliação da capacidade de autonomia e independência de cada um. Além de haver previsão de uma reavaliação periódica.

É neste novo contexto, então, que deve se materializar as sentenças judiciais que decretam que um sujeito está sob a curatela de um outro; assim como, o exercício do encargo pelo curador.

Novata como esta nova legislação que balança o ideário consolidado trazendo alterações em tantos paradigmas, é a atual área de atuação do Serviço Social no Tribunal de Justiça do Rio de Janeiro (TJRJ) criada para dar suporte ao setor que tem como atribuição responder pela curatela de várias pessoas.

Instituída em 2018, esta equipe técnica formada por assistentes sociais é responsável pelo acompanhamento às pessoas que foram colocadas sob a curatela do tutor judicial mediante sentença judicial. Neste contexto o profissional é acionado a atuar para além da perícia social, realiza acompanhamento/intervenções técnicas através dos instrumentos técnico operativos como a escuta qualificada a partir das entrevistas, visitas domiciliares, institucionais e articulação com a rede intersetorial, interinstitucional, rede comunitária e/ou familiar que estão presentes no cotidiano de vidas dos curatelados. Segundo Guerra (2000), os instrumentos são elementos "necessários à atuação técnica, através dos quais os assistentes sociais podem efetivamente objetivar suas finalidades". 
O público atendido é composto por pessoas cuja curatela é exercida pelo tutor judicial e o âmbito de atuação territorial é a cidade do Rio de Janeiro. Convém destacar as especificidades da população de nossa intervenção: adultos e idosos com deficiência e/ou transtorno mental, de ambos os sexos, inseridos em instituições públicas, privadas e filantrópicas.

O perfil socioeconômico é diverso, com pessoas cuja renda decorre de benefícios previdenciários (aposentadoria por invalidez, pensão por morte), benefícios assistenciais (bolsa família, benefício de prestação continuada) e benefícios indenizatórios (bolsas de desinstitucionalização para pacientes vitimados por longa internação psiquiátrica). Há também aqueles que não contam com renda própria, pois ainda aguardam o deferimento de benefícios requeridos.

A equipe técnica vem enfrentando desafios durante esse período de pandemia em seu cotidiano profissional em relação ao atendimento presencial aos curatelados assistidos pela Tutoria Judicial. Muitos que se encontram institucionalizados nos equipamentos públicos, e que em sua maioria são usuários da saúde mental, estão mantendo o distanciamento social e as visitas estão suspensas até o presente momento. Os contatos e/ou acompanhamentos continuam ocorrendo, mas de forma remota com os curatelados e através de reuniões virtuais com a rede intersetorial de serviços para acompanhamento dos casos.

Um aspecto relevante do trabalho em rede é a articulação das instituições que estão presentes no cotidiano de vida dos curatelados que deveriam ter acesso, tanto pelo Sistema de Justiça quanto pelo Poder Executivo. No trabalho articulado do Serviço Social com a Central de Tutoria Judicial, considerando a realidade de vida dos curatelados, é de suma importância o trabalho em rede, as discussão de caso, para tentativas de redução de danos nas situações de vulnerabilidades em decorrência do sofrimento psíquico, rompimentos dos laços familiares e/ou comunitários, isolamento social e privações socioeconômicas ou até mesmo acesso a direitos tais como: documentação civil, requerimento de benefício, entre outros. $O$ trabalho em rede possibilita a integralidade da atenção aos sujeitos sociais em vulnerabilidades ou risco social.

Para Pereira (2014), a intersetorialidade:

[...] é um termo dotado de vários significados e possibilidades de aplicação. No Brasil dos últimos vinte anos a intersetorialidade vêm despertando 
crescente interesse intelectual e político, particularmente no âmbito das políticas sociais públicas. Sua defesa nesse âmbito apoia-se no reconhecimento de que a relação concertada entre "setores" implica mudanças substanciais na gestão e impactos dessas políticas, bem como ampliação da democracia e da cidadania social (PEREIRA, 2014, p.23).

A Intersetorialidade corresponde além da articulação entre os setores da política, a participação social, o diálogo com a sociedade civil, visando a emancipação da população assistida.

Outro aspecto desafiador nesses meses de teletrabalho tem sido 0 bombardeio de diversos webnários, palestras, lives e cursos na modalidade virtual debatendo o exercício profissional em tempos de Covid-19. Se por um lado todos foram convocados a participar e isso acarretou em disponibilizar horas a mais de trabalho. Por outro lado, contribuiu para a formação continuada permitindo refletir de forma coletiva sobre os limites e desafios no processo de trabalho do serviço social durante esse período de pandemia e acirramento das desigualdades sociais. O Código de Ética Profissional do assistente social em seu inciso $X$ afirma sobre o "compromisso com a qualidade dos serviços prestados à população e com o aprimoramento intelectual, na perspectiva da competência profissional" (BRASIL, [2012]).

O caos propiciado pela chegada da Covid-19 em terras brasileiras não tem relação apenas com o colapso do Sistema Único de Saúde (SUS), mas estabelece estreita conexão com o modo como as relações sociais são fundamentadas na sociabilidade do capital. No Brasil, país de capitalismo subdesenvolvido e periférico, as contradições e desigualdades são pungentes. Segundo Antunes (2020), meses antes do início da pandemia, 16,7 milhões de domicílios brasileiros tinham dois salários mínimos como renda mensal. A força de trabalho totalizava 106,2 milhões, dos quais 11,6 milhões estavam desempregados.

Dados da Pesquisa Nacional por Amostras de Domicílio (PNAD) do ano de 2019, apontam que o Brasil tem cerca de 10 milhões de trabalhadores no mercado de trabalho informal (IBGE, 2019). E em pesquisa realizada pelo Instituto Brasileiro de Economia da Fundação Getúlio Vargas (IBRE/FGV), este número tem aumentado significativamente nos últimos meses do ano de 2020 (FUNDAÇÃO GETÚLIO VARGAS, c2020). 
Logo, há que se salientar que trabalho informal dialoga com trabalho desprotegido, sem quaisquer tipos de garantias e direitos trabalhistas constitucionalmente assegurados. A precariedade da oferta de trabalho no mercado formal empurra parcela expressiva da classe que vive de seu trabalho para a informalidade, para os pequenos "bicos", para os aplicativos de prestação de serviço de transporte privado urbano e de entrega de comida, dentre outros tipos de ocupação de baixa remuneração, de total desproteção e progressivo aviltamento das condições de vida daqueles que precisam vender sua força de trabalho e, também, de suas famílias.

Em levantamento realizado no mês de maio de 2020 (IFOOD, 2020), o valor mínimo de cada entrega realizada é de cinco reais $(R \$ 5,00)$ e que o valor da tarifa é baseado no seguinte cálculo: retirada do pedido no restaurante; entrega para o cliente e a distância percorrida. E o valor pode sofrer alterações de acordo com o número de pedidos, o perfil da cidade, a hora e o dia da semana, bem como o modal (carro, moto, patinete ou bicicleta).

Nessa perspectiva, evidencia-se que a agravamento das expressões da questão social ${ }^{6}$ apresentam, ainda, sensível recorte de gênero e etnia, visto que em decorrência da divisão sociossexual do trabalho, no Brasil trabalhadoras domésticas, $68 \%$ das trabalhadoras domésticas são negras (ANTUNES, 2020) e, como é possível assistir cotidianamente nos meios de comunicação, muitas são as violações de direitos às quais essa parcela da classe trabalhadora é submetida ${ }^{7}$.

\section{A EXPERIÊNCIA DA ATUAÇÃO PROFISSIONAL NA EXECUÇÃO DO DIREITO DE FAMÍLIA}

De acordo com Petrini (2009), o tema família constitui um desafio às investigações das Ciências Humanas. Ao longo dos tempos, tal questão está entre as

\footnotetext{
6 Segundo lamamoto (1997, p. 27), a Questão Social pode ser definida como: O conjunto das expressões das desigualdades da sociedade capitalista madura, que têm uma raiz comum: a produção social é cada vez mais coletiva, o trabalho torna-se mais amplamente social, enquanto a apropriação dos seus frutos se mantém privada, monopolizada por uma parte da sociedade.

7 Tais violações são historicamente datadas e, obviamente, modificadas ao longo do tempo, se tornam cada vez mais simbólicas e sofisticadas. Mas são fruto da história, pois ao abordar a história do América Latina, Galeano (2014), afirma que na Cuba do século XVIII, "os capatazes descarregavam seus látegos de couro ou cânhamo nas costas das escravas grávidas que tinham cometido faltas, mas não sem antes deitá-las de boca pra baixo, com a barriga enfiada num buraco, para que não fosse danificada a "peça" nova em gestação" (GALEANO, 2014, p. 126).
} 
que mais têm causado polêmica. As diversas posições sociais e políticas fazem referência a ela, existindo quase sempre uma preocupação em tudo o que lhe diz respeito. Para alguns, a família, como instituição, está relacionada ao inevitável conservadorismo, outros a consideram um recurso para a pessoa e para a sociedade, por inserir o indivíduo em processos fundamentais da construção da identidade (PETRINI, 2009, p.1).

Os tradicionais arranjos familiares, que antes eram vistos sob o patamar econômico e da reprodução, tendo o casamento como a única forma de instituir família, sofreram inúmeras mutações. Neste sentido, Petrini (2009, p. 16) observa que,

O crescimento de novos estilos de vida e de novos arranjos familiares atesta que a sociedade contemporânea passa por um processo sociocultural de rediferenciação e de re-definição da família com relação a outras relações primárias (PETRINI, 2009, p. 16).

Faz-se necessário destacar, que a família contemporânea se caracteriza por variedades de formas, que documentam a inadequação dos diversos modelos da tradição, para compreender os grupos familiares da atualidade. Tudo isto resulta na diversidade de valores que se pode encontrar em nossa cultura e na variedade de constituição de arranjos familiares, ocasionando a oscilação da percepção de família. Deste modo, Petrini (2009) coloca que,

\footnotetext{
A família contemporânea passa por mudanças em muitas dimensões, especialmente nas relações intergeracionais e de intimidade caracterizadas pela maior expressão dos afetos e busca da autonomia de seus membros, a embasar a construção subjetiva individual (PETRINI, 2009, p. 1).
}

No Tribunal de Justiça do Estado do Rio de Janeiro, em conformidade ao disposto no Provimento 80/2009, em seu artigo $1^{\circ}$, as Equipes Técnicas Interdisciplinares foram formadas por Assistente Sociais e Psicólogos, tendo como finalidade auxiliar os juízos no âmbito de sua atribuição (RIO DE JANEIRO (Estado), 2009). Nesse sentido, a criação dos Núcleos Regionais (NUR) tem por objetivo organizar o trabalho das equipes técnicas em todas as comarcas do Estado. Assim, hoje o Tribunal de Justiça do Estado do Rio de Janeiro tem treze Núcleos Regionais, todos eles com Equipe Técnica Interdisciplinar, equipes formadas por profissionais de Serviço Social e Psicologia, que são responsáveis por auxiliar os juízes nas matérias de sua competência profissional. 
Nesse sentido, a Equipe Técnica Interdisciplinar Cível (ETIC) do 5№ NUR Volta Redonda é responsável por atender seis Comarcas, a saber: Volta Redonda, Barra Mansa, Resende, Itatiaia, Porto Real e Pinheiral no atendimento a famílias.

Nas referidas Comarcas, os Assistentes Sociais são demandados para atuar, maioritariamente, nos processos da justiça de família que, em sua maioria, compreendem situações familiares de conflitos, disputas, violência, maus tratos, rompimentos de vínculos familiares e sofrimentos, bem como, em dinâmicas relacionais não tão conflituosas, nas ações de regularização de guarda, em acordos de visitação e de compartilhamento de guarda.

O assistente social desenvolve trabalhos que podem incluir orientação, articulações e encaminhamentos à rede social, contatos e entrevistas com membros da rede familiar entre outros. Porém, a solicitação institucional mais comum à área do Serviço Social diz respeito aos subsídios para a decisão judicial, por meio do estudo social (FÁVERO, [2009]).

A análise dos dados (apresentada no parecer social) implica na avaliação da relação que pode ser estabelecida entre esta rede de relações sociais (no âmbito público e privado) e o reconhecimento/garantia/violação dos direitos fundamentais dos sujeitos que se constituem partes dos processos judiciais, estabelecendo mediação, na sua dimensão reflexiva, com o contexto histórico que determina tal relação.

Portanto, pode-se dizer que os processos refletem histórias, sendo estas muitas vezes marcadas por vivências de violações de direitos, vulnerabilidades e precarização das condições de vida dos sujeitos atendidos.

O perfil da população atendida no 5 NUR são famílias em situação de vulnerabilidades que acessam a justiça por diferentes demandas, tais como, disputa de guarda, regulamentação de visitas, interdição, alteração de registro civil, negatória de paternidade, entre outras.

Nesse sentido, é necessário um esforço teórico metodológico de compreender a questão social na perspectiva de totalidade, evitando a sua fragmentação em "problemas sociais", que leva a parcialização das causas e consequências das demandas colocadas ao profissional, culpabilizando os indivíduos pelas situações vivenciadas.

Elencar categorias de análise que possibilitem compreender a dinâmica desta diversidade vivenciada no cotidiano de nossa prática profissional é o desafio que se 
coloca a fim de se trabalhar de acordo com o projeto ético-político do Serviço Social para a consolidação da efetivação de direitos dos sujeitos atendidos.

Com o início da crise sanitária, o processo de trabalho dos Assistentes Sociais na área judiciária sofreu diversas mudanças. A primeira delas, decorrente da imperiosa necessidade de isolamento social, foi a alteração na forma do atendimento prestado aos jurisdicionados. Se antes da pandemia, o contato com a população se dava presencialmente, a partir do mês de março do ano de dois mil e vinte, o diálogo entre profissional e usuário da justiça foi transferido para a esfera virtual. Mediante contatos telefônicos e vídeo chamadas, dia após dia, a condução do trabalho técnico assumia novos contornos e possibilidades.

O incremento das Tecnologias da Informação e Comunicação (TICs) não é uma novidade no judiciário, haja vista que a informatização do acesso, bem como a migração dos processos físicos para a plataforma virtual não teve início neste ano. $O$ que chamamos atenção aqui é para as mudanças que atingiram diretamente a relação dos Assistentes Sociais com a população atendida.

Muitas foram as tensões e inquietações dos profissionais com relação à garantia dos direitos dos jurisdicionados, tais como a questão do sigilo, pois a partir do momento que os atendimentos passaram a ser realizados de forma remota é impossível certificar que os relatos realizados pelos sujeitos sociais atendidos são materializados em ambiente protegido.

Dessa maneira, se ao passo que no trabalho presencial tinha-se como premissa, a depender da natureza da ação judicial, viabilizar a escuta de crianças e adolescentes, no teletrabalho, optou-se por não proceder ao atendimento virtual dos referidos sujeitos de direitos a fim de preservar o sigilo e, sobretudo, para protegê-los de possíveis situações constrangedoras no ambiente doméstico. Faz-se oportuno ressaltar que tal opção não se objetivou de forma isolada, mas sim na esteira de recomendações do Conselho Nacional dos Direitos da Criança e do Adolescente (CONANDA) / Distrito Federal.

Logo, há que se registrar o não atendimento de crianças e adolescentes nos processos no âmbito do Direito de Família tem como princípio a proteção e a garantia de que tais indivíduos sociais em condição peculiar de desenvolvimento não sejam revitimizados em decorrência de seus discursos. Não se trata de silenciá-los, mas de intervir na direção da salvaguarda de seus direitos. 
Identifica-se, também, aumento no número de processos de regulamentação de visitas e de guarda unilateral a partir do mês de maio de 2020. Ações judiciais decorrentes de divórcios, as quais são atravessadas por intenso conflito, o que torna a tramitação difícil e lenta, pois os envolvidos recusam-se ao acordo.

No mês de agosto do corrente ano, dos oitenta processos distribuídos para os profissionais de Serviço Social da Equipe Técnica Interdisciplinar Cível da Comarca de Volta Redonda, trinta eram de natureza de Regulamentação de Visitas e os vinte e cinco restantes relacionados a pleitos de guarda unilateral.

Dentre os desafios colocados nessa situação, tem-se a necessidade de cumprimento do isolamento social para não transmissão voluntária do vírus, bem como a necessidade de proteger não só as crianças e adolescentes, mas de igual modo, os demais membros do grupo familiar. Assim, como emitir opinião técnica aos juízes, em ações de regulamentação de visitas, quando um dos genitores relata que os avós do infante residem consigo, são do grupo de risco, mas o outro responsável familiar, na incompreensão de tais determinações, não abre mão de ter contatos presenciais e periódicos com o filho? Este é apenas um dos muitos exemplos que delimitam o grau de dificuldade do trabalho técnico desenvolvido pelos assistentes sociais.

Noutro giro, a equipe técnica durante esse período de pandemia vem enfrentando dificuldades com relação a recursos tecnológicos. Muitos assistentes sociais precisaram comprar computador, contratar serviço de internet mais potente, chip para o celular com a finalidade de preservar minimamente sua privacidade.

Percebe-se que o incremento das TICs, no início da pandemia, se deu de forma muito rápida e sem planejamento contribuindo para uma tendência à desprofissionalização do trabalho. Sendo assim, os profissionais têm precisado se organizar, com os próprios recursos, para assegurar o caráter profissional do trabalho realizado.

Preservar a privacidade, a saúde mental de forma a qualificar, ainda que com muitas limitações, o atendimento aos usuários.

Outro aspecto relevante a sinalizar diante das dificuldades impostas por essa nova realidade é a dificuldade no acesso à população usuária que é ainda mais alijada dos recursos tecnológicos. 
Considera-se necessário destacar que as expressões da questão social que se apresentam nas dinâmicas familiares são apreendidas no agir profissional do assistente social de forma privilegiada, in loco, aproximando os técnicos das manifestações concretas de convivência nos diferentes grupos familiares e/ou comunitários dos usuários do Judiciário.

\title{
5 CONSIDERAÇÕES FINAIS
}

Neste artigo, buscou-se refletir sobre os desafios que atravessam o cotidiano de trabalho dos profissionais de Serviço Social no Tribunal de Justiça, visto que estabelecer a mediação entre as demandas institucionais e aquelas apresentadas pela população atendida exige competências teórico-metodológicas, técnicooperativas e ético-políticas afinadas aos princípios norteadores do projeto éticopolítico da profissão, na perspectiva da defesa intransigente dos direitos humanos.

Entende-se que o caminho do agir profissional é permeado pela correlação de forças sociais na luta pelo prevalecimento dos diferentes interesses dos grupos sociais, considerando que o Poder Judiciário, enquanto instituição estruturada pelo Estado, historicamente desenvolve sua ação de caráter normatizador e regulador dos conflitos sociais.

De acordo com o Teixeira ([2009]),

\begin{abstract}
Mesmo diante das adversidades é que devemos reafirmar nosso projeto ético-político, pois ele fornece os insumos para enfrentar as dificuldades profissionais a partir dos compromissos coletivamente construídos pela categoria (TEIXEIRA, [2009], p.12).
\end{abstract}

É importante sinalizar que mesmo com limitações a equipe técnica busca estratégias para atuar de forma comprometida com o projeto ético-político profissional em defesa dos direitos dos sujeitos que acessam a justiça. De acordo com lamamoto (2011) "A realidade hoje exige um profissional qualificado, que amplie e reforce sua competência crítica, que não seja somente executivo, mas que reflita, avalie, pesquise e decifre o real".

Entende-se que na atualidade o desafio maior que permeia os direitos não é mais de garanti-los juridicamente, pois já estão assegurados na Constituição Federal de 1988 e nas Declarações Universais e Internacionais dos Direitos Humanos. 
Conforme adverte Trindade (2002), o mais complexo é efetivar os direitos diante de uma sociedade capitalista regida por uma política neoliberal que mercantiliza os direitos ao invés de efetivá-los.

Assim, finaliza-se, socializando algumas destas reflexões, nascidas no exercício da nossa atuação profissional, superando uma prática conservadora e policialesca, representando assim, um esforço de contribuir nas grandes batalhas que a conjuntura atual apresenta no sentido de defesa da democracia, da liberdade e do Estado de direitos.

É certo que após esta pandemia nada mais será como antes, mas difícil ainda prever como de fato será, já que a história se escreve a muitas mãos e no cotidiano da vida.

\section{REFERÊNCIAS}

ANTUNES, R. Coronavírus: o trabalho sob fogo cruzado. 1 ed. São Paulo: Boitempo, 2020. E-book.

BRASIL. Código de ética do/a assistente social: Lei 8.662/93 de regulamentação da profissão. 10 ed. rev. e atual. [Brasília]: Conselho Federal de Serviço Social, [2012]. Disponível em: http://www.cfess.org.br/arquivos/CEP_CFESS-SITE.pdf. Acesso em: 29 set. 2020.

BRASIL. Decreto no 17.943-a, de 12 de outubro de 1927. Consolida as leis de assistencia e protecção a menores. Rio de Janeiro, RJ: Presidência da República, 1927. Disponível em: http://www.planalto.gov.br/ccivil_03/decreto/19101929/d17943a.htm. Acesso em: 29 set. de 2020.

BRASIL. Direitos humanos na Internet. Lei das XII Tábuas. DHNET, c1995. Disponível em: http://www.dhnet.org.br/direitos/anthist/12tab.htm. Acesso em: 29 set. de 2020.

BRASIL. Lei $\mathrm{n}^{\circ}$. 13.146, de 6 de julho de 2015. Institui a Lei Brasileira de Inclusão da Pessoa com Deficiência (Estatuto da Pessoa com Deficiência). Brasília, DF: Presidência da República, 2015. Disponível em:

http://www.planalto.gov.br/ccivil_03/_ato2015-2018/2015/lei/13146.htm. Acesso em: 29 set. 2020.

BRASIL. Lei $\mathbf{n}^{\circ}$. 8.662, de 7 de junho de 1993. Dispõe sobre a profissão de Assistente Social e dá outras providências. Brasília, DF: Presidência da República, 1993. Disponível em: http://www.planalto.gov.br/ccivil_03/leis//8662.htm. Acesso em: 29 set. 2020. 
CHUAIRI, S. H. Assistência jurídica e serviço social: reflexões interdisciplinares.

Revista Serviço Social e Sociedade, São Paulo, n. 67, p. 124-144, set. 2001.

ESTATÍSTICAS do coronavírus (COVID-19). Última atualização 03/12/2020

Microsoft Bing, [S.I.], 2020. Disponível em:

https://www.bing.com/search?q=mortos+pela+covid+19+Brasil\&form=ANNTH1\&refig $=155 \mathrm{~b} 6687 \mathrm{c} 35143 \mathrm{e} 39944 \mathrm{e} 8 \mathrm{e} 04 \mathrm{f} 3 \mathrm{fbb} 15 \& \mathrm{sp}=-$

$1 \&$ ghc $=1 \& p q=$ mortos + pela+covid $+19+$ brasil \&sc $=1-$

$27 \& q s=n \& s k=\& c v i d=155 b 6687 c 35143 e 39944 e 8 e 04 f 3 f b b 15$. Acesso em: 3 dez.

2020.

FÁVERO, E. T. O Estudo Social: fundamentos e particularidades de sua construção na Área Judiciária. In: CONSELHO FEDERAL DE SERVIÇO SOCIAL (org.) 0

Estudo Social em Perícias, Laudos e Pareceres Técnicos: contribuição ao debate no Judiciário, Penitenciário e na Previdência Social. São Paulo: Cortez, 2003.

FÁVERO, E. T. Instruções sociais de processos, sentenças e decisões. [S.I.: s.n.], [2009]. p. 1-34. Disponível em:

http://www.cressrn.org.br/files/arquivos/8W95x91Vh0eXhsCK46ge.pdf. Acesso em: 29 set. 2020. Originalmente publicado em: Conselho Federal de Serviço Social. Serviço Social: direitos e competências. Brasília: CFESS: ABEPESS, 2009.

FUNDAÇÃO GETÚLIO VARGAS. Pesquisas. Portal FGV, c2020. Disponível em: https://portal.fgv.br/pesquisas. Acesso em: 3 dez. 2020.

GALEANO, E. Veias abertas na América latina. Tradução de Sergio Faraco. [S.I.]: L\&PM, 2014.

GUERRA, Y. A instrumentalidade do Serviço Social. 10. ed. São Paulo: Cortez, 2000.

IAMAMOTO, M. V. Ensino e Pesquisa no Serviço Social: desafios na construção de um processo de formação. In: REVISTA Temporalis. São Paulo: Cortez, 1997. (Cadernos Abess, n. 6).

IAMAMOTO, M. V. Questão Social, família e juventude: desafios do trabalho do assistente social na área sócio-jurídica. In: SALES, M. A.; MATOS, M. de C.; IAMAMOTO, M. V. A questão social no capitalismo. Revista Temporalis, Brasília: ABEPSS, n. 3, p. 9-32, 2011.

IAMAMOTO, M. V. Renovação e Conservadorismo no Serviço Social: Ensaios críticos. 12 ed. São Paulo: Cortez, 2013.

IBGE. Pesquisa Nacional por Amostra de Domicílios Contínua. 4 ed. Rio de Janeiro: IBGE, 2019. (Notas técnicas, versão 1,5). Disponível em:

https://biblioteca.ibge.gov.br/visualizacao/livros/liv101651_notas_tecnicas.pdf. Acesso em: 3 dez. 2020. 
IFOOD: o principal aplicativo de food delivery do Brasil. Machine, [S.I.], 4 de setembro de 2020. Disponível em: https://machine.global/ifood-food-delivey/. Acesso em: 29 set. 2020 .

INSTITUTO PEREIRA PASSOS. Painel Rio COVID-19: boletim 03/12/2020. Data.Rio, Rio de Janeiro, 2020. Disponível em: https://www.data.rio/app/painel-riocovid-19. Acesso em: 3 dez. 2020.

MINAYO, M. C. S. de; DESLANDES, S. F.; GOMES, R. (org.). Pesquisa social: Teoria, método e criatividade. 21 ed. Petrópolis, RJ: Vozes, 1994.

NETTO, J. P. Capitalismo monopolista e Serviço Social. São Paulo: Cortez, 1982. $165 p$.

PEREIRA, P. A. P. A intersetorialidade das políticas sociais na perspectiva dialética. In: MONNERAT, G. L.; ALMEIDA, N. L. T. de; SOUZA, R. G. de. A intersetorialidade na agenda das políticas sociais. Campinas, São Paulo: Papel Social, 2014.

PETRINI, J. C.; MOREIRA, L. V. de C.; ALCANTARA, M. A. R. Família na contemporaneidade: uma análise conceitual. 1 ed. São Paulo: Paulinas, 2009.

RIO DE JANEIRO (Estado). Provimento CGJ no 80/2009. Resolve que as Equipes Técnicas Interdisciplinares serão formadas por Assistentes Sociais e Psicólogos, tendo como finalidade auxiliar os juízos no âmbito de sua atribuição, e dá outras providências. Rio de Janeiro, RJ: Poder Judiciário do Estado do Rio de Janeiro, 2009. Disponível em:

http://www4.tjrj.jus.br/atosoficiais/provimentocgj/PROVIMENTOCGJ-80-2009TEXTOCOMPILADO.pdf. Acesso em: 29 set. 2020.

SILVA, M. I. Estado \& Sociedade Civil: Contribuições para a construção de uma perspectiva emancipatória. Boletin Electronico Sura, n. 120, p. 1-22, 2006.

Disponível em: http://www.ts.ucr.ac.cr/binarios/sura/sura-0120.pdf. Acesso em: 29 set. 2020.

TEIXEIRA, J. B.; BRAZ, M. O projeto ético-político do Serviço Social. [S.I.: s.n.], [2009]. p. 1-18. Disponível em: http://www.abepss.org.br/arquivos/anexos/teixeirajoaquina-barata_-braz-marcelo-201608060407431902860.pdf. Acesso em: 29 set. 2020. Originalmente publicado em: Conselho Federal de Serviço Social. Serviço Social: direitos e competências. Brasília, DF: CFESS: ABEPESS, 2009.

TRINDADE, J. D. de L. História social dos direitos humanos. São Paulo: Editora Petrópolis, 2002.

YASBEK. M. C. As ambiguidades da assistência social brasileira após dez anos de LOAS. Revista Serviço Social e Sociedade, São Paulo, ano 15, n. 77, 2004. 